\title{
Adverse Event Onset Date
}

National Cancer Institute

\section{Source}

National Cancer Institute. Adverse Event Onset Date. NCI Thesaurus. Code C93716.

The date (and time) on which an adverse event began. 